\title{
Cenário Tecnológico da Biorremediação de Hidrocarbonetos Assistida pelo Uso de Fungos e Extratos Vegetais: Prospecção Tecnológica
}

\author{
Technological Scenario of Hydrocarbon Bioremediation Assisted by the \\ Use of Fungi and Plant Extracts: Technological Prospecting
}

\author{
Milton Santos Cardoso Filho \\ Odete Gonçalves ${ }^{1}$ \\ Camila Rozene de Almeida Santos ${ }^{1}$ \\ Olivia Maria Cordeiro de Oliveira ${ }^{1}$ \\ Ícaro Thiago Andrade Moreira ${ }^{1}$ \\ ${ }^{1}$ Universidade Federal da Bahia, Salvador, BA, Brasil
}

\begin{abstract}
Resumo
A presente pesquisa tem como objetivo realizar a prospecção do atual cenário tecnológico no uso de fungos e extratos vegetais nos processos de biorremediação de hidrocarbonetos. Para o desenvolvimento dessa prospecção, foram retiradas informações do banco de dados Web of Science - Espacenet, no Registro Europeu de Patentes (EPO), uma plataforma em nível Europeu que contém as principais informações sobre as patentes depositadas. A pesquisa foi feita por meio da utilização de palavras-chave e dos códigos de indexação B09C1/10 - Microbiologicamente, biologicamente ou usando enzimas e C02F2101/32 - Hidrocarbonetos ou petróleo. Como resultado, foram obtidos: a quantidade de patentes depositadas durantes os anos, quais os principais inventores, que empresas têm desenvolvido novas tecnologias e qual a aplicabilidade dessas invenções. Constatou-se que o desenvolvimento biotecnológico voltado para a biorremediação de áreas impactadas por hidrocarbonetos só obteve maior investimento a partir de 2013, tendo maior destaque para o ano de 2016 com 20 invenções depositadas.
\end{abstract}

Palavras-chave: Prospecção. Biotecnologias. Extrato Vegetal. Fungos.

\begin{abstract}
This research aims to explore the current technological scenario in the use of fungi and plant extracts in hydrocarbon bioremediation processes. For the development of this prospecting, the information was taken from the Web of Science - Espacenet database, in the European Patent Register (EPO), a platform at the European level where it contains the main information about the patents filed. The research was done using keywords and indexing codes B09C1/10 - Microbiologically, biologically or using enzymes and C02F2101/32 - Hydrocarbons or petroleum, as a result the number of patents filed during the years was obtained, which are the main ones inventors, which companies have developed new technologies and the applicability of these inventions. It was found that the biotechnological development aimed at the recovery of areas impacted by hydrocarbons only obtained greater investment from 2013, with greater emphasis for the year 2016 with 20 inventions deposited.
\end{abstract}

Keywords: Prospecting. Biotechnologies. Plant Extract. Fungi.

Área Tecnológica: Geoquímica. Biotecnologia. Engenharias. 


\section{Introdução}

Segundo o International Tanker Owners Pollution Federation (ITOPF, 2020), o volume total de petróleo perdido para o meio ambiente registrado em 2019 foi de aproximadamente 1.000 toneladas, com a maior parte desse volume associada a grandes derramamentos. A presença de petróleo em ecossistemas marinhos e costeiros acarreta diversos impactos negativos à saúde ambiental das regiões diretamente atingidas, principalmente por causa dos Hidrocarbonetos Policíclicos Aromáticos (HPAs), uma das frações constituintes do petróleo bruto (MAZEAS; BUDZINSKI, 2001).

Os HPAs são considerados poluentes orgânicos tóxicos com potencial carcinogênico e mutagênico, podendo afetar diretamente a saúde da fauna, da flora e dos seres humanos (PONGPIACHAN et al., 2018; KONG et al., 2018; MANARIOTIS; KARAPANAGIOT; CHRYSIKOPOULOS, 2011; WOLSKA et al., 2012). E pelo fato de serem lipossolúveis, eles possuem predisposição à bioacumulação em tecido animal, causando uma série de efeitos negativos à saúde (ALEGBELEYE; OPEOLU; JACKSON, 2017).

A Agência de Proteção Ambiental dos EUA (EPA) listou 16 HPAs como poluentes de controle prioritário, Acenafteno acenaftileno, antraceno, benzo(a)antraceno, benzo(a)pireno, benzo(b) fluoranteno, benzo(ghi)perileno, benzo(k)fluoranteno, criseno, dibenzo(a,h)antraceno, fenantreno, fluoranteno, fluoreno, indeno(1,2,3-cd)pireno, naftaleno e pireno (EPA, 2014).

Devido aos HPAs de origem petrogênica estarem cada vez mais presentes na natureza, diversos pesquisadores vêm estudando os impactos em várias matrizes ambientais e em métodos para recuperar essas áreas de forma sustentável por meio do desenvolvimento de processos $e$ de invenções com potencial de serem utilizadas na biodegradação de petróleo em diferentes ambientes (ZENG et al., 2018, LOFTHUS et al., 2018, LI; LI; LIU, 2017).

Nos últimos anos, diversas técnicas de biorremediação vêm sendo utilizadas nos processos de biodegradação de petróleo, e o uso de microrganismos nesses processos vêm apresentando resultados positivos (LOUISA, 2010). Nas pesquisas relacionadas à biorremediação de solos e sedimentos contaminados por petróleo, a bioaumentação e a bioestimulação são as técnicas mais difundidas.

A bioaumentação consiste na introdução de microrganismos com capacidade de utilizar o contaminante como fonte de energia e/ou com capacidade de converter o contaminante em formas menos nocivas, consumindo-os e, consequentemente, diminuindo a sua concentração ao longo do tempo (DZIONEKE; WOJCZYZYNKS; GUZIK, 2016), enquanto a bioestimulação visa elevar a atividade microbiana, com o intuito de acelerar e de aumentar os percentuais de biodegradação por meio da adição de uma fonte menos complexa de nutrientes (LIU et al., 2018; MADUEÑO et al., 2011; WU et al., 2016).

A prospecção tecnológica tem sido considerada fundamental para promover e direcionar o desenvolvimento científico, pois é possível, por meio da prospecção de patentes, levantar as tecnologias existentes, as lacunas a serem preenchidas, as principais concorrentes e as suas variações, os principais inventores, os países que mais depositam invenções, as principais empresas depositantes, entre outros dados. Dessa forma, pode-se avaliar se a tecnologia em questão já foi desenvolvida, se já foi apropriada ou se já está sendo utilizada pela sociedade (QUINTELLA et al., 2011).

Esta pesquisa tem o objetivo de avaliar tendências tecnológicas voltadas para os processos de biorremediação de área impactadas por hidrocarbonetos com o uso de fungos e de extrato vegetal como bioestimulante na biodegradação de HPAs. 


\section{Metodologia}

A metodologia consistiu na busca de patentes no banco de dados Web of Science - Espacenet, que é uma plataforma on-line e gratuita para pesquisa e pedidos de patentes desenvolvida pelo Escritório Europeu de Patentes (EPO), o qual possui documentos de diversos países contendo todas as informações relacionadas às invenções tecnológicas. A investigação reportou com o uso de palavras-chave e a combinação de códigos indexados, os dados obtidos foram utilizados na confecção dos quadros e figuras deste artigo.

Foi utilizado o Portal de Periódicos CAPES/MEC na revisão bibliográfica deste artigo que atualmente disponibiliza a instituições de ensino e pesquisa no Brasil o melhor da produção científica internacional de forma on-line e gratuita. Com um acervo de mais de 45 mil títulos com texto completo, 130 bases referenciais, 12 bases dedicadas exclusivamente a patentes, além de livros, enciclopédias e obras de referência, normas técnicas, estatísticas e conteúdo audiovisual (CAPES; MEC, 2019).

Feita a prospecção, foram identificados quais os principais países responsáveis pelo depósito de invenções, quais são as suas aplicabilidades, os principais autores e as indústrias interessadas na tecnologia em questão. As palavras-chave utilizadas na busca foram "bioremediation" (biorremediação), "biodegradation" (biodegradação), "PAH" (HPA), "vegetable extract" (Extrato vegetal), "plant extract" (Extrato de planta), "fungus" (fungos) e estão apresentadas na Tabela 1.

Tabela 1 - Palavras-chaves, códigos de indexação e números de patentes encontrados com a sua combinação no banco de dados Web of Science - Espacenet - EPO

\begin{tabular}{|c|c|c|c|c|c|c|c|c|c|c|c|c|c|c|}
\hline 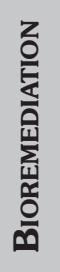 & 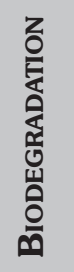 & $\frac{T}{\Lambda}$ & 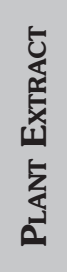 & 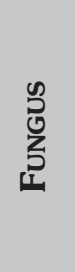 & ஓे & 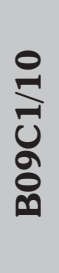 & 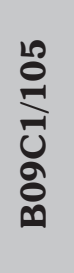 & 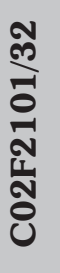 & 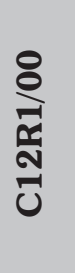 & 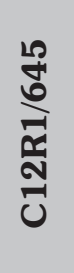 & 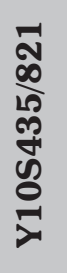 & 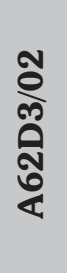 & 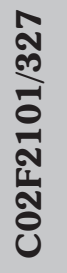 & TotaL \\
\hline & $X$ & & & & & & & & & & & & & 5.975 \\
\hline & & & & & & $X$ & & & & & & & & 1.670 \\
\hline & & $X$ & & & & & & & & & & & & 928 \\
\hline & & & & & & $X$ & & $X$ & & & & & & 320 \\
\hline & & & & & $X$ & & & & & & & & $X$ & 78 \\
\hline & & & & & & $X$ & & $X$ & $X$ & & & & & 60 \\
\hline & & & & & & & & & & $X$ & & $X$ & & 29 \\
\hline $\mathrm{X}$ & & & & $X$ & & & & & & & & & & 23 \\
\hline & & & & & & $X$ & & $X$ & & & & $X$ & & 15 \\
\hline & & & & & & $X$ & & & & & $X$ & & & 14 \\
\hline$X$ & & $X$ & & & & & & & & & & & & 9 \\
\hline $\mathrm{X}$ & & & $X$ & & & & & & & & & & & 3 \\
\hline & & $X$ & & $X$ & & & & & & & & & & 3 \\
\hline
\end{tabular}

Fonte: Elaborada pelos autores deste artigo (2019) 
Os códigos de indexação de interesse e suas combinações estão apresentados no Quadro 1 com o número de invenções encontradas no universo dos registros de patentes para os quais foram utilizados operadores booleanos $A N D$ e OR com o intuito de capturar conteúdos mais específicos dessa prospecção.

Quadro 1 - Descrição dos códigos de indexação na busca das patentes na Web of Science - Espacenet - EPO

\begin{tabular}{|c|c|}
\hline CóDIGo & DESCRIÇÃO \\
\hline A62D3/02 & Por métodos biológicos, ou seja, processos usando enzimas ou microrganismos \\
\hline C12R $1 / 00$ & Processos usando microrganismos \\
\hline Y10S435/821 & Microrganismos utilizados na destruição de resíduos perigosos ou tóxicos \\
\hline C12R1/645 & Usando fungo \\
\hline B09C $1 / 105$ & Remoção de contaminantes de solo contaminado por fungos ou plantas \\
\hline C02F2101 & Natureza do contaminantes \\
\hline C02F2101/32 & Hidrocarbonetos ou petróleo \\
\hline C02F2101/327 & Hidrocarbonetos Policíclicos Aromáticos [HPAs] \\
\hline B09 & Eliminação de resíduos sólidos; Reclamação de solo contaminado \\
\hline B09C1/00 & Recuperação de solo contaminado \\
\hline C12R1 & Processos usando microrganismos \\
\hline Y10S435/911 & Usando fungo \\
\hline
\end{tabular}

Fonte: Elaborado pelos autores deste artigo (2019)

O levantamento patentário por prospecção científica tecnológica foi realizado em setembro de 2019. O grupo de patentes selecionadas para a prospecção corresponde à utilização dos códigos de indexação B09C1/10, que caracterizam B como realizando operações + 09C como reclamação de solo contaminado, totalizando B09C1/10 como microbiologicamente, biologicamente ou usando enzimas, o que significa tornar o solo contaminado inofensivo por meio de tratamento biológico.

Tal código se justifica por que é um subtópico dos códigos B09C1 (Recuperação de solos contaminados) e C02F2101/32 que caracteriza C como Química + 02 como tratamento de resíduos + F2 como a natureza do contaminante, os compostos orgânicos, totalizando C02F2101/32 como Hidrocarbonetos, por exemplo, óleo. Além desses códigos, foram investigados outros e todos os códigos de indexação utilizados na prospecção encontram-se no Quadro 2 juntamente com a sua descrição.

Como resultado da prospecção, foram geradas figuras com os dados obtidos a partir do Espacenet, o tratamento desses dados foi realizado utilizando-se o software Microsoft Excel 2016. 


\section{Resultados e Discussão}

Pela análise do conteúdo foi possível identificar o avanço do desenvolvimento tecnológico na área ambiental nos últimos anos e encontrado um total de 320 patentes, com 148 famílias, com uma cobertura da base de dados de $99 \%$, com esse tipo de tecnologia sendo solicitado em média em 2,16 países.

A Figura 1 demonstra as empresas e as universidades que mais depositaram patentes pertinentes à prospecção, entre as empresas, destaca-se a Innovative Environmental Technologies (IET), voltada para o desenvolvimento e a implementação de alternativas corretivas in situ e ex situ, utilizando-se de equipamentos projetados, patenteados e licenciados tendo 15 patentes depositadas nos últimos 23 anos de atuação.

A IET conta com sete depósitos de patentes, US2017239699, BR112015028317, US2018001358, US2018093308, EP2969977, EP2994428 e US2015183670, relacionadas à estabilização de metais tóxicos, remoção de compostos orgânicos semivoláteis em solos, lamas, águas subterrâneas, águas de produção e águas residuais por meio de processos de oxidação, atenuação biológica e uso de enzimas na biodegradação (IET, 2018).

Outras empresas também se destacaram, como a Thermocyclomics LLC, com uma patente, a WO2013116830A1, voltada para a biorremediação de contaminantes orgânicos em solo e sedimentos ou águas residuais contaminadas. A Remediation Products apresenta uma patente, a US20180297871A1, de uma composição para remediação in situ de solo e água subterrânea contaminada com hidrocarbonetos, na qual descreve um método de biorremediação para áreas, contendo hidrocarbonetos e compostos halogenados pela introdução de microrganismos com capacidade de biodegradar hidrocarbonetos.

E a segunda patente, a US20190217354A1, é sobre uma composição para remediação in situ do solo e águas subterrâneas contaminadas com hidrocarbonetos por meio do uso de um material adsorvente, um composto contendo sulfato e um sistema com nutrientes para promover microrganismos anaeróbios facultativos.

Entre as universidades, duas se destacaram: a Zhejiang University e a Nanjing University, ambas chinesas. A China atualmente é uma potência mundial possuindo seis instituições de ensino superior e ocupando o "top 100" das melhores universidades do mundo (ABMES, 2019). A Zhejiang University ocupa $5^{a}$ posição das melhores universidades chinesas, com mais de 2.000 patentes de invenções depositadas até 2017 (ZJU, 2019), e a Nanjing University ocupa a $7^{\mathrm{a}}$ posição.

Identificou-se que a Zhejiang University possui, nesta prospecção, três patentes relacionadas à imobilização de enzimas para serem utilizadas na biodegradação de petróleo e na aplicação de bactérias e biossurfactantes na degradação de n-hexadecano; e a Nanjing University tem quatro patentes de uso de cepas bacterianas como agente de biodegradação de petróleo. 
Figura 1 - Depósito de patentes por empresa e universidades

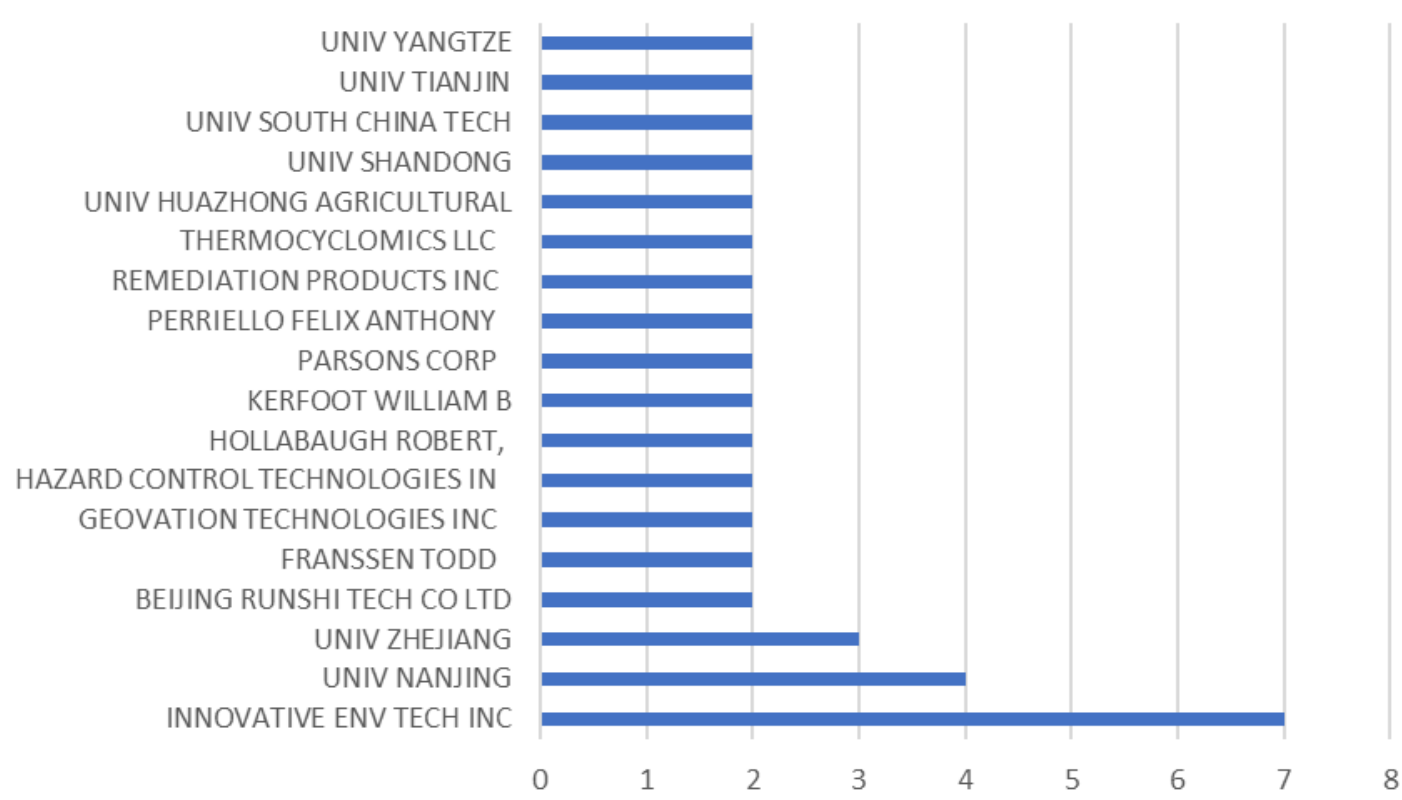

Fonte: Elaborada pelos autores deste artigo (2019)

Pela pesquisa relacionada ao uso de extratos vegetais na biorremediação de compostos orgânico, foi encontrada apenas uma patente: "Natural-origin enzymatic bioremediation with wide applicability, the substrate being an environment consisting of extracts from oleaginous vegetable sources added to an isomer mixture", com inventores brasileiros e depositada como uma Patent Cooperation Treaty (PCT).

Essa invenção traz uma inovação técnica para a manipulação de elementos enzimáticos de origem natural desenvolvidos, utilizando as enzimas para biopolimerização de um ambiente específico com características biodegradáveis, usando como substrato elementos constituídos por extratos de fontes vegetais oleaginosas adicionadas a uma mistura de isómero.

Quanto ao cenário brasileiro, nesta prospecção, foi encontrada uma única patente depositada pela Universidade Salvador, em dezembro de 2017, sobre um Sistema para tratamento de águas, solos e sedimentos poluídos por petróleo, metais pesados, efluentes industriais e lodo de esgoto por meio da aplicação de espécies vegetais e de microrganismos bentônicos.

$\mathrm{Na}$ evolução do depósito de patentes, Figura 2, houve um pequeno aumento no final da década de 1990 com uma média de uma patente por ano, com destaque para o ano de 2003, com oito patentes registradas relacionadas ao uso de processos naturais na biodegradação de hidrocarbonetos. Logo após esse período, houve um declínio, mas com um novo aumento considerável no ano de 2013, e no ano de 2016 houve o maior número de patentes depositadas, 20 patentes foram encontradas, e a grande maioria das patentes voltadas para a utilização de microrganismos como agentes de remoção e biodegradação de compostos orgânicos tóxicos. 
Figura 2 - Depósito de patentes por ano

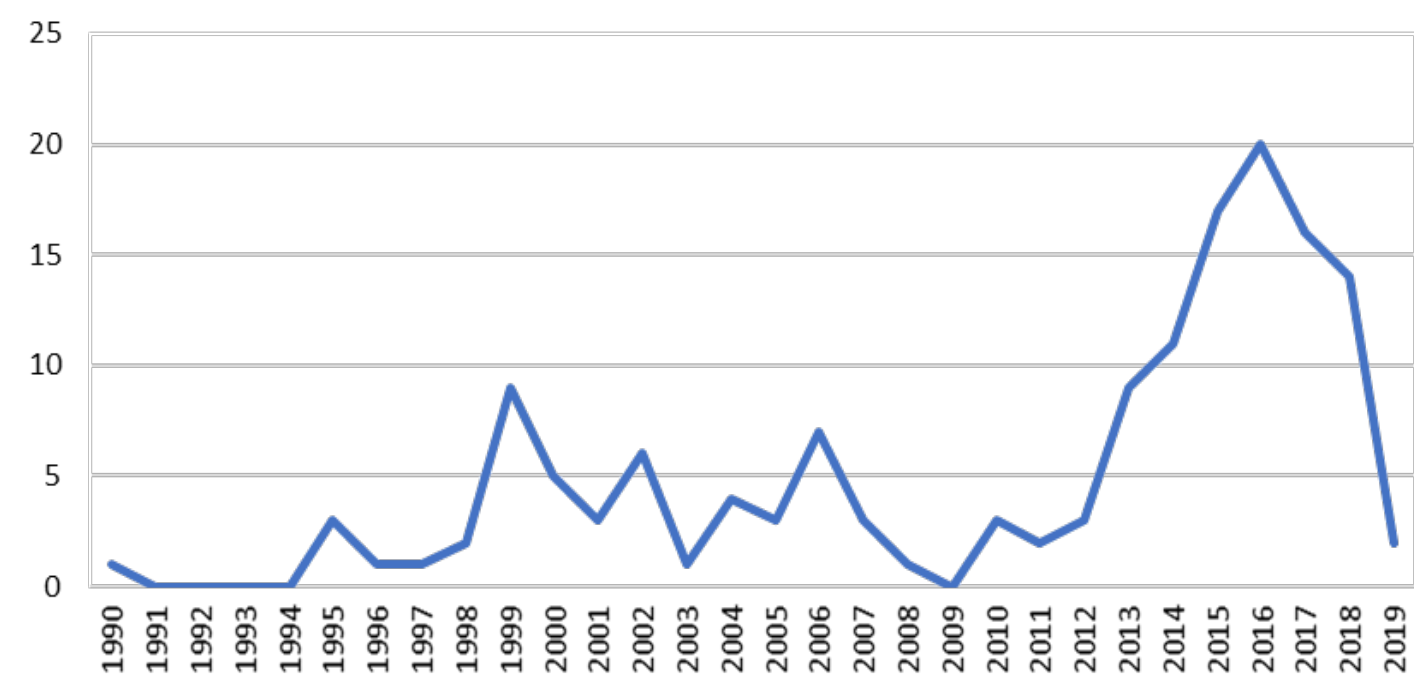

Fonte: Elaborada pelos autores deste artigo (2019)

Essa baixa na década de 1990 pode ser justificada devido ao alto investimento de países, como Estados Unidos, Japão, França e Reino Unido, na decodificação do código genético humano ao longo de 10 anos no Programa Genoma humano. Dessa forma, as pesquisas foram direcionadas e, como consequência, isso limitou o desenvolvimento de biotecnologias, pois o desenvolvimento tecnológico ficou voltado para produtos relacionados à medicina e à farmácia (MAYOR, 1992).

Enquanto isso, o aumento de patentes no final da década de 1990 e o início dos anos 2000 pode ter ocorrido por causa do grande volume de petróleo perdido entre 1991 e 1996, cerca de 732,000 toneladas de petróleo (ITOPF, 2019). Como consequência disso, foi criada uma demanda de tecnologias para a remoção do petróleo e para a recuperação desses ambientes contaminados devido a uma série de derramamentos.

Além disso, ressalta-se o fato de que, em 1992, a agenda ambiental começava a ganhar destaque entre as nações, o que acarretou na Conferência das Nações Unidas, popularmente conhecida como Eco-92, que contou com a participação de 178 países, na qula foi discutida a criação de parâmetros para a proteção da biodiversidade. Assim, os países seriam responsáveis por desenvolver e fornecer tecnologias para se alcançar um novo modelo de desenvolvimento que fosse sustentável, principalmente no sentido de reduzir os padrões de consumo de combustíveis fósseis (OLIVEIRA, 2012).

O aumento após 2014 pode ter ocorrido devido à quantidade de substâncias geradas nos processos industriais nos últimos anos, já que causam impactos negativos ao meio ambiente. Em vista disso, quantidades consideráveis de resíduos industriais começaram a ser produzidos e, consequentemente, afetando a capacidade ambiental de autodepuração desses poluentes, criando, assim, a necessidade em investir em novas tecnologias que fossem baratas e ecologicamente corretas para a remediação de diversas áreas impactadas por atividades antropogênicas (GODECK; NAIME; FIGUEIREDO, 2012).

A primeira patente nesta prospecção foi depositada pelo Japão, nela descreve-se um processo de purificação e processamento de materiais contaminados. E a última invenção depositada em 2019 pelo Canadá é sobre a aplicação de uma bactéria do gênero Pseudomonas que foi isolada de um solo contaminado com petróleo como agente de biodegradação de hidrocarbonetos. 
Em seguida, encontrou-se uma patente depositada pelos Estados Unidos que descreve um método de bioremediação de solos e águas subterrâneas contendo hidrocarbonetos e compostos halogenados por meio de composições. Essa patente descreve uma metodologia tecnológica que conta com um consórcio microbiano com capacidade de biodegradar hidrocarbonetos, um segundo consórcio com capacidade de degradar compostos halogenados, um composto orgânico e um terceiro consórcio com capacidade de biodegradar o composto orgânico.

Na Figura 3 estão apresentados os países que possuem o maior número de patentes depositadas. Os Estados Unidos lidera o ranking com 55 patentes relacionadas à biorremediação de compostos orgânicos com a utilização de microrganismos, com fibras de plantas, e na utilização de resíduos agrícolas como fonte nutricional na biorremediação de hidrocarbonetos.

Figura 3 - Principais países depositantes de patentes

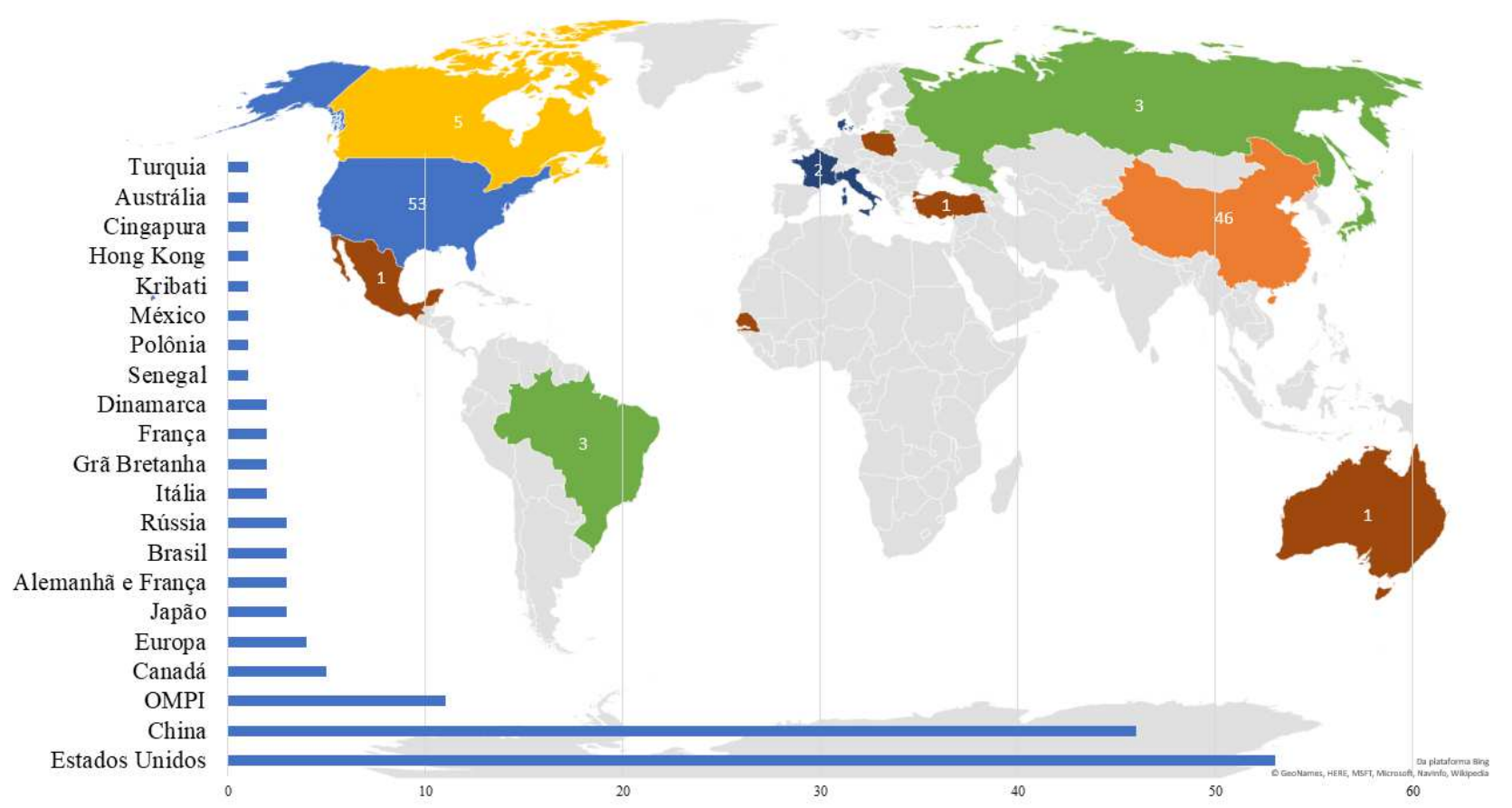

Fonte: Elaborada pelos autores deste artigo (2019)

Os Estados Unidos, atualmente, são uma das maiores economias mundiais que mais investem em tecnologia, e a maioria de suas patentes são depositadas por empresas. Enquanto a China possui 46 patentes relacionadas à utilização de culturas microbianas na biorremediação, na recuperação de petróleo por meio de processos microbianos, métodos para tratamentos de solos contaminados com petróleo, imobilização de enzimas degradadoras de petróleo etc., com todas as suas patentes depositadas pelas universidades do país.

Destaca-se que os Estados Unidos e a China são os países que possuem o maior número de depósito de patentes. Luna et al. (2015) encontraram um resultado semelhante, segundo eles, a China e os Estados Unidos são os maiores depositantes de patentes relacionados à recuperação de áreas impactadas por petróleo, também foi observado que a maioria dessas patentes estava relacionada ao uso de microrganismos no tratamento desse contaminante.

E, na pesquisa realizada por Quintella, Mata e Lima (2019), uma avaliação do desenvolvimento tecnológico na biorremediação de petróleo com o uso de fungos, também se identificou 
que a maioria das patentes são originárias da China e dos Estados Unidos e que a grande maioria tem as bactérias, os fungos e as enzimas como agentes promotores da biorremediação.

Esse alto número de invenções pode ser justificado pelo fato de estes serem países com alto investimento em pesquisas de P\&D. Com isso, os EUA superaram os 31 bilhões de reais de investimento nas áreas da ciência da vida, engenharias, física, ciências ambientais, ciências da computação e matemática, psicologia, ciências sociais e outros (NSF, 2019). Já a China investiu 685 bilhões de reais em educação superior (CHINA, 2019), o que justifica o alto depósito de patentes.

Outro fator que pode ter influenciado esse grande investimento da China e dos Estados Unidos em biotecnologias para a recuperação dessas áreas contaminadas é a grande produção e consumo de petróleo e derivados nesses países. Segundo o Instituto Brasileiro de Petróleo e Gás (IBP, 2020), os Estados Unidos e a China lideraram o consumo de petróleo em 2019, somando juntos $34 \%$ do consumo mundial.

Entre os principais processos e produtos, Figura 4, destacam-se as invenções referentes a métodos de biorremediação, que se referem a metodologias que descrevem a forma de aplicação de agentes oxidativos, estimulantes e adsortivos em um processo de remediação, que são as que representam a maior parte de todas as patentes desta prospecção, obtendo o total de $56 \%$ de todas as invenções, seguido do uso de bactérias com $30 \%$.

Figura 4 - Principais processos e produtos das patentes selecionadas

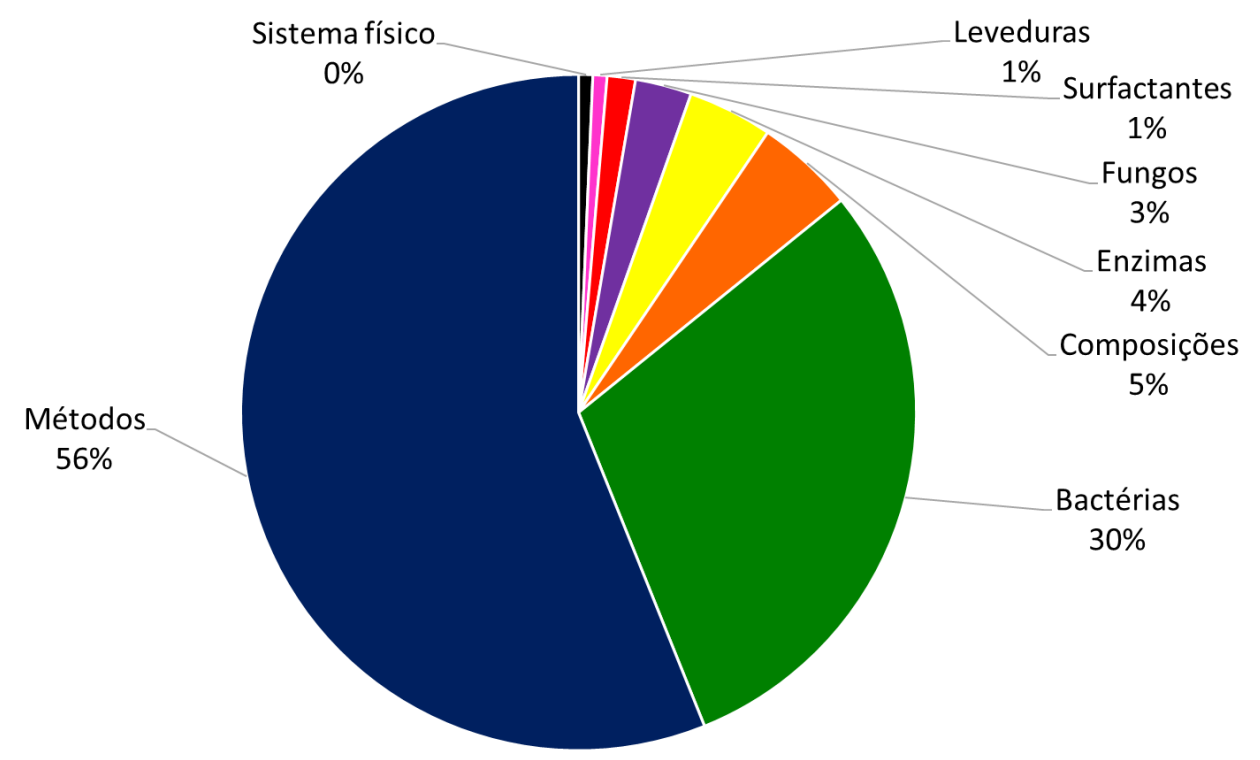

Fonte: Elaborada pelos autores deste artigo (2019)

Nesta prospecção, observou-se que o uso de fungos em tecnologias de biorremediação é algo ainda pouco expressivo em comparação ao uso de bactérias, apesar de, atualmente, o seu uso já ser algo difundido, apresentando bons resultados no uso de fungos de diversos gêneros na biodegradação de hidrocarbonetos (FRANCESCA; MOLLEA, 2019). 


\section{Considerações Finais}

Nesta prospecção foi possível concluir que a tendência tecnológica nos processos de biorremediação de hidrocarbonetos está relacionada a métodos específicos e ao uso de bactérias hidrocarbonoclásticas. O uso de fungos e extratos vegetais foram considerados tecnologias inexpressivas em relação às demais devido ao baixo número de patentes encontrado, o que necessariamente não quer dizer que o uso de fungos ou de extratos sejam tecnologias ineficientes, pois diversas pesquisas vêm apontando o seu potencial nos processos de biorremediação.

O baixo depósito de invenções relacionadas ao uso de fungos e extrato vegetais é um indicativo de que essa seja uma área pouco desenvolvida ou em desenvolvimento, dando perspectivas para a exploração desse nicho tecnológico.

Os Estados Unidos e a China são os países que possuem o maior número de patentes depositadas, um resultado já esperado, por causa do alto investimento em educação e desenvolvimento tecnológico desses países.

Já no Brasil foi encontrada apenas uma patente nacional, provavelmente devido ao baixo investimento em pesquisas aplicadas à biorremediação, quando comparado aos Estados Unidos e à China, revelando a necessidade de mais investimentos em tecnologias que utilizem os microrganismos ou os bioprodutos na biodegradação de hidrocarbonetos no Brasil.

\section{Referências}

ABMES - ASSOCIAÇÃO BRASILEIRA DE MANTENEDORAS DE ENSINO SUPERIOR. Educação na China. [2019]. Disponível em: https://www.abmes.org.br/abmes-internacional/experience/4/ china/links/detalhe/40. Acesso em: 8 out. 2019.

AlEGBeleye, O. O.; OPEOLU, B. O.; JACKSON, A. V. Polycyclic Aromatic Hydrocarbons: a Critical Review of Environmental Occurrence and Bioremediation. Environmental Assessment, [s.l.], v. 60, n. 4. p. 758-783, 2017.

ANTONIS, K.; MICHAEL, S. Processo de oxidação química e atenuação biológica para o tratamento de meios contaminados. Innovative Environmental Tech Inc. BR n. 112015028317. Depósito 2 de maio de 2014. Publicação 25 de julho de 2017.

CAPES - COORDENAÇÃO DE APERFEIÇOAMENTO DE PESSOAL DE NÍVEL SUPERIOR; MEC - MINISTÉRIO DA EDUCAÇÃO. Acervo, 2019. Disponível em: http://www-periodicos-capes-govbr.ezl.periodicos.capes.gov.br/index.php?option $=$ com_pcollection\&Itemid=105. Aceso em: 6 out. 2019.

CHINA. China investe mais em educação em 2018. [2019]. Disponível em: www.chinahoje.net/ china-investe-mais-em-educacao-em-2018/. Acesso em: 9 out. 2019.

DZIONEKE, A.; WOJCZYZYNKS, D.; GUZIK, U. Natural carriers in bioremediation: A review. Electronic Journal of Biotechnology, [s.l.], v. 19, n. 5, 2016.

EPA - UNITED STATES ENVIROMENTAL PROTECTION AGENCY. Priority Polluant List. 2014. Disponível em: https:/www.epa.gov/sites/production/files/2015-09/documents/priority-pollutant-listepa.pdf. Acesso em: 12 jan. 2019. 
FRANCESCA, B.; MOLLEA, C. Mycoremediation in Soil. Environmental Chemistry and Recent Pollution Control Approaches, Saldarriaga-Noreña, p. 1-16, 2019.

GODECKE, M. V.; NAIME, R.H.; FIGUEIREDO, J. A. S.; O consumismo e a Geração de Resíduos Sólidos Urbanos no Brasil. Rev. Elet. em Gestão, Educação e Tecnologia Ambiental, [s.l.], v. 8, n. 8, p. 1.700-1.712, 2012.

HAZEN, T. C.; PRINC, R. C.; MAHMOUDI, N. Marine Oil Biodegradation. Enviromental Science Tecnology, [s.l.], v. 50, n. 5, p. 2.121-2.129, 2016.

IET - INNOVATIVE ENVIROMENTAL TECNOLOGIES, Inc. Patents: masking the world safe through innovation. [2018]. Disponível em: http://www.iet-inc.net/patents/. Acesso em: 5 dez 2018.

IBP - INSTITUTO BRASILEIRO DE PETRÓLEO E GÁS. Maiores consumidores de petróleo e LGN em 2019. [2020]. Disponível em: https://www.ibp.org.br/observatorio-do-setor/snapshots/ maiores-consumidores-de-petroleo-e-lgn-em-2019/. Acesso em 21 ago. 2020.

ITOPF - INTERNATIONAL TANKER OWNERS POLLUTION FEDERATION. Oil Tanker Spill Statistics 2018. [2020]. Disponível em: https://www.itopf.org/knowledge-resources/data-statistics/ statistics/. Acesso em: 9 ago. 2019.

ITOPF - INTERNATIONAL TANKER OWNERS POLLUTION FEDERATION. Oil tanker spill statistics 2019. Special edition: 50 years of data, 2019. Disponível em: https://www.itopf.org/ knowledge-resources/data-statistics/. Acesso em: 22 ago. de 2020.

JUSTIA. Patentes. [2018]. Disponível em: https://patents.justia.com/assignee/thermocyclomicsllcUS2013295650. Acesso em: 5 dez. 2018.

KONG, L. et al. Biochar accelerates PAHs biodegradation in petroleum-polluted soil by biostimulation strategy. Journal of Hazardous Materials, [s.l.], v. 343, p. 276-284, 2018.

LI, J.; LI, F.; LIU, Q. PAHs behavior in surface water and groundwater of the Yellow River estuary: Evidence from isotopes and hydrochemistry. Chemosphere, [s.l.], v. 178, p. 143-153, 2017.

LIU, Q. et al. Bioremediation of petroleum-contaminated soil using aged refuse from landfills. Waste Management. [S.l.: s.n.], 2018.

LOFTHUS, S. et al. Biodegradation in seawater of PAH and alkylphenols from produced water of a North Sea platform. Chemosphere, [s.l.], v. 206, p. 456-473, 2018.

LOUISA, W. P. Review: In situ and bioremediation of organic pollutants in aquatic sediments.

Journal of Hazardous Materials, [s.l.], v. 177, n, 1-3, p. 81-89, 2010.

LUNA, S. et al. Cenário Tecnológico para remediação de áreas afetadas com petróleo utilizando extrato vegetal da família araceae. Cadernos de Prospecção, Salvador, v. 8, n. 3, p. 531-543, 2015.

MADUEÑO, L. et al. Isolation and characterization of indigenous soil bacteria for bioaugmentation of PAH contaminated soil of semiarid Patagonia, Argentina. International Biodeterioration \& Biodegradation, [s.l.], v. 65, n. 2, p. 345-351, 2011.

MANARIOTIS, I. D.; KARAPANAGIOT, H. K.; CHRYSIKOPOULOS, C. V. Degradation of PAHs by high frequency ultrasound. Water Research, [s.l.], v. 45, p. 2.587-2.594, 2011.

MAYOR, Federico. As biotecnologias no início dos anos noventa: êxitos, perspectivas e desafios. Estud. Av., São Paulo, v. 6, n. 16, p. 7-28, Dec. 1992. 
MAZEAS, L.; BUDZINSKI, H. Polycyclic aromatic hydrocarbon $13 \mathrm{C} / 12 \mathrm{C}$ ratio measurement in petroleum and marine sediments: Application to standard reference materials and a sediment suspected of contamination from the Erika oil spill. Journal of Chromatography, [s.l.], v. 923, p. 164-176, 2001.

MUELLER, J.; SCALZI, M.; KARACHALIOS, A. Methanogenesis control during environmental applications using antimethanogenic reagents. Innovative Environmental Technologies Inc. US n 2018093308. Depósito 29 de novembro de 2017. Publicação 5 de abril de 2018.

NOLAND, S. Method of in situ remediation of soils using a bioremediation composition including a time release material. Remediation Produtc Inc. US n. 20190217354A1. Depósito 18 de julho de 2018. Publicação 22 de março de 2019.

NOLAND, S.; ELLIOT, B. Compositions for removing hydrocarbons and halogenated hydrocarbons from contaminated environment. Remediation Products Inc. US n. 20180297871A1. Depósito 18 de junho de 2018. Publicação18 de outubro de 2018.

NSF - NACIONAL SCIENCE FUNDATION. NSF FY 2018 Performance and Financial Highlights. [2019]. Disponível em: https://www.nsf.gov/publications/pub_summ.jsp?ods_ key $=$ nsf19003. Acesso em: 7 out. 2019.

O'DRISCOLL, K. et al. Bioremediation of persistent organic pollutants using thermophilic bacteria. Thermocyclomics, Llc. WO n. WO2013116830A1. Depósito 4 de fevereiro de 2013. Publicação 8 de agosto de 2013.

OLIVEIRA, L. D. Da Eco-92 à Rio +20: uma breve avaliação de duas décadas. Boletim Capineiro de Geografia, [s.l.], v. 2, n. 3, p. 479-499, 2012.

PONGPIACHAN, S. et al. Chemical characterization of polycyclic aromatic hydrocarbons (PAHs) in 2013 Rayong oil spill-affected coastal areas of Thailand, Environmental Pollution, [s.l.], v. 233, p. 992-1.002, 2018.

QUINTELLA, C. M. et al. Prospecção Tecnológica como uma Ferramenta Aplicada em Ciência e Tecnologia para se Chegar à Inovação. Revista Virtual de Química, [s.l.], v. 3, n. 5, p. 406-415, 2011.

QUINTELLA, C. M.; MATA, A. M.; LIMA, L. C. P. Overview of bioremediation with technology assessment and emphasis on fungal bioremediation of oil contaminated soils. Journal of Environmental Management, [s.l.], v. 241, p. 156-166, 2019.

SCALZI, M.; KARACHALIOS, A. Chemical Oxidation and Biological Attenuation Process for the Treatment of Contaminated Media. Innovative Environmental Technologies Inc. US n. 20170239699A1. Depósito 29 de agosto de 2016. Publicação 24 de agosto de 2017.

SCALZI, M.; KARACHALIOS, A. Heavy metal stabilization and methane inhibition during induced or naturally occurring reducing conditions in contaminated media. Innovative Environmental Technologies Inc. US n. 2015183670. Depósito 2 de novembro de 2014. Publicação 2 de julho de 2015 .

SCALZI, M.; KARACHALIOS, A. Hemmung einer methanproduktion durch anaerobe reduktive dechlorierung. Innovative Environmental Technologies Inc. EP n. 2969977. Depósito 2 demaio de 2014. Publicação 20 de janeiro de 2016. 
SCALZI, M.; KARACHALIOS, A. Verfahren für chemische oxidierung und biologische dämpfung zur behandlung verunreinigter medien. Innovative Environmental Technologies Inc. EP n. 2994428. Depósito 2 de maio de 2014. Publicação 16 de março de 2015.

SCALZI, M.; MUELLER, J.; KARACHALIOS, A.; Inhibition of methanogenesis in reducing environments. Innovative Environmental Technologies Inc. US n. 001358. Depósito 17 de janeiro de 2017. Publicação 4 de janeiro de 2018.

WIPO - WORLD INTELLECTUAL PROPERTY ORGANIZATIONS. 4220. (US20180297871)

Composições para remoção de hidrocarbonetos e hidrocarbonetos halogenados a partir de ambientes contaminados. [2018]. Disponível em: https://patentscope.wipo.int/search/en/detail.jsf ;jsessionid =4C3C9A054A889035F785C48FC84FAC6F.wapp2nC?docId=US231858547\&recNum $=4220 \&$ office $=\&$ queryString $=\&$ prevFilter $=\&$ sortOption $=$ Pub + Date + Desc $\&$ maxRec $=71343184$. Acesso em: 4 dez. 2018.

WOLSKA, L. et al. Sources and fate of PAHs and PCBs in the marine environmet. Critical Reviews in Environmental Science and Technology, [s.l.], v. 42, p. 1.172-1.189, 2012.

WU, M. et al. Bioaugmentation and biostimulation of hydrocarbon degradation and the microbial community in a petroleum-contaminated soil. International Biodeterioration \& Biodegradation, [s.l.], v. 107, p. 158-164, 2016.

ZENG, Q. et al. Distribution, fate and risk assessment of PAHs in water and sediments from an aquaculture- and shipping-impacted subtropical lake, China. Chemosphere, [s.l.], v. 201, p. 612$620,2018$.

ZJU - ZHEJIANG UNIVERSITY. Research. [2019]. Disponível em: www.zju.edu.cn/english/research/ list.htm. Acesso em: 9 out. 2019.

\section{Sobre os Autores}

\section{Milton Santos Cardoso Filho}

E-mail: cardososmilton@gmail.co

Mestre em Geoquímica Petróleo e Meio Ambientes pela Universidade Federal da Bahia em 2020. Área de formação em Ciências Exatas e da terra.

Endereço profissional: Escola Politécnica da UFBA, Rua Prof. Aristídes Novis, n. 2, Federação, Salvador, BA. CEP: 40210-630.

\section{Odete Gonçalves}

E-mail: odetegoncalves7@hotmail.com

Doutora em Biotecnologia Industrial pela Rede Nordeste de Biotecnologia em 2018. Área de formação: Ciências biológicas, Universidade Federal da Bahia.

Endereço profissional: Programa de Pós-Graduação em Propriedade Intelectual e Transferência de Tecnologia para a Inovação, Av. Araújo Pinho, n. 39, Canela, Salvador, BA. CEP: 40110-150. 


\section{Camila Rozene de Almeida Santos}

E-mail: camila.rozene@hotmail.com

Ensino médio completo pelo Colégio da Polícia Militar Francisco Pedro de Oliveira em 2013.

Endereço profissional: Instituto de Geociências (IGEO) Universidade Federal da Bahia, Av. Adhemar de Barros, s/n, Campus Universitário de Ondina, Salvador, BA. CEP: 40170-110.

\section{Olívia Maria Cordeiro de Oliveira}

E-mail: olivia@ufba.br

Doutora em Geoquímica Ambiental, Brasil, pela Universidade Federal Fluminense em 2000. Área de formação: Ciências exatas e da terra.

Endereço profissional: Instituto de Geociências (IGEO) Universidade Federal da Bahia, Av. Adhemar de Barros, s/n, Campus Universitário de Ondina, Salvador, BA. CEP: 40170-110.

\section{Ícaro Thiago Andrade Moreira}

E-mail: icarotam@gmail.com

Doutor em Geologia Ambiental, Hidrogeologia e Recursos Hídricos pela Universidade Federal da Bahia em 2014. Endereço profissional: Escola Politécnica da Universidade Federal da Bahia, Rua Prof. Aristides Novis, n. 2, Federação, Salvador, BA. CEP: 40210-630. 